discussion papers

FS IV $02-11$

Intermediation in Innovation

Heidrun C. Hoppe *

Emre Ozdenoren **

* University of Hamburg

** University of Michigan

June 2002

ISSN Nr. 0722 - 6748

Forschungsschwerpunkt

Markt und politische Ökonomie

Research Area

Markets and Political Economy 
Zitierweise/Citation:

Heidrun C. Hoppe and Emre Ozdenoren, Intermediation in Innovation, Discussion Paper FS IV 02-11, Wissenschaftszentrum Berlin, 2002.

Wissenschaftszentrum Berlin für Sozialforschung gGmbH, Reichpietschufer 50, 10785 Berlin, Germany, Tel. (030) 25491 - 0 Internet: www.wz-berlin.de 


\title{
ABSTRACT
}

\section{Intermediation in Innovation 1}

\author{
by Heidrun C. Hoppe ${ }^{2}$ and Emre Ozdenoren ${ }^{3}$
}

The paper offers a new theoretical framework to examine the role of intermediaries between creators and potential users of new inventions. Using a model of universityindustry technology transfer, we demonstrate that technology transfer offices can provide an opportunity to economize on a critical component of efficient innovation investments: the expertise to locate new, external inventions and to overcome the problem of sorting 'profitable' from 'unprofitable' ones. The findings may help explain the surge in university patenting and licensing since the Bayh-Dole Act of 1980. Furthermore, the study identifies several limitations to the potential efficiency of intermediation in innovation.

Keywords: Intermediation, Market Microstructure, Matching, Uncertainty, Innovation, Patent Licensing.

JEL Classification: D4, D8, L12, L13, O32

1 The work in this paper was conducted in part while Heidrun Hoppe was visiting Northwestern University, whose hospitability and support is gratefully acknowledged. We would like to thank Rich Jensen, Jesper Roine, and Don Siegel for very useful dicussions. We have also bene...ted from helpful comments of Claude d'Aspremont, Mort Kamien, Kai Konrad, Martin Pesendorfer, Dan Spulber, and Marie Thursby.

2 From October 2002: University of Bonn, Wirtschaftstheoretische Abteilung II, Lennéstr. 37, D53113 Bonn, Germany, Tel: 0049228-739242. Before: University of Hamburg, IAW, Von-MellePark 5, D-20146 Hamburg, Germany, Tel: 004940-42838-5571, E-Mail: hoppe@econ.unihamburg.de.

3 University of Michigan, Department of Economics, 611 Tappan Street, Ann Arbor, MI 48109-1220, USA, Tel: +1-734-647-5606, E-Mail: emreo@umich.edu. 


\section{Intermediation in Innovation}

In diesem Papier stellen wir ein neues theoretisches Modell zur Analyse der Rolle von Intermediären zwischen Erfindern und potentiellen Nutzern von Erfindungen vor. Für den Transfer von Erfindungen aus Universitäten in den Industriebereich zeigen wir, daß Technologietransfer-Stellen den Marktteilnehmern die Möglichkeit bieten, sich die Kosten für den Aufbau der Expertise, neue externe Erfindungen zu lokalisieren und evaluieren, zu teilen. Die Ergebnisse unserer Studie können dazu beitragen, die signifikante Zunahme der Universitätspatente und -lizensen seit dem Bayh-Dole-Act von 1980 in den USA zu erklären. Darüber hinaus diskutieren wir Wohlfahrtswirkungen der Aktivität von Innovations-Intermediären. 


\section{Introduction}

One major constraint to the success of many invention-based ventures proves to be the high degree of uncertainty about their profitability (Arrow, 1962; Kamien and Schwartz, 1982). Apart from technical difficulties, it is often hard to assess the commercial value of inventions that may lead to entirely new products without knowing the demand for it. As a consequence, potential investors act on expected values, and profitable new technology may not be adopted due to pessimistic beliefs. In this paper, we examine the role that intermediaries between creators, financiers, and users of new technology can play in mitigating the problem of uncertainty.

Obviously, such intermediaries exist. Technology transfer offices (TTOs) intermediate between university researchers and industrial firms. They assess the commercial potential of research results, such as the potential applications of an invention, its competitive advantages, novelty and likely markets, and seek firms that have the capability, interest and resources to take on the development of the invention. Normally, they contact several prospective licensees and pursue one of them. Finally, they negotiate a licensing contract. ${ }^{1}$ Similarly, venture capitalists play a role as intermediaries between innovative entrepreneurs and private investors, concentrating in industries where information gaps between entrepreneurs and investors are commonplace. Their activity includes the evaluation of innovative ventures and the investment in selected start-up projects. ${ }^{2}$ Other examples include underwriters who use their expertise and network of contacts to locate investors with high valuations for the securities of a new start-up firm, and technologybased business incubators who intermediate between new start-up firms, financiers, and industrial customers.

Despite their obvious presence, such innovation intermediaries have received little attention in the theoretical literature. ${ }^{3}$ In this paper, we offer a theoretical framework to explore the conditions under which innovation intermediaries emerge and analyze the role they can play in reducing the uncertainty problem in the process of new technology adoption. We exemplify the issues in the context of university-industry technology transfer, and present what is perhaps the simplest model that still captures the essence of the problem. The model assumes that a potential market for invention fails to exist due to uncertainty

\footnotetext{
${ }^{1}$ See, e.g., Association of University Technology Managers Web Page, http://www.autm.net, and the Office of Technology Licensing Web Page, http://otl.stanford.edu/about/resources/history.html.

${ }^{2}$ For a comprehensive survey over the venture capital literature, see Gompers and Lerner (1999).

${ }^{3}$ There is growing, mainly empirical, literature on financial intermediation in the process of innovation and new technology adoption (see, e.g. Gompers and Lerner, 1999). For a comprehensive survey over the intermediation theory literature, see Spulber (1999).
} 
about the profitability of adoption. On the other hand, the benefits from adopting profitable inventions are, if realized, in aggregate large enough to compensate an agent, called the intermediary, for acquiring the ability to locate new inventions, identify those that are profitable, and recommend them to potential investors. However, because of asymmetric information the intermediary might claim a high quality even when the invention is of low quality. Moreover, the intermediary may have an incentive to do so whenever it does not bear the cost of adopting the invention. As a consequence, investors' payments to the intermediary may not be large enough to recoup the cost of acquiring the expertise in the first place, making active intermediation in innovation impossible. The model admits two types of equilibria under certain conditions: innovation equilibria in which an intermediary invests in expertise, evaluates inventions, and matches the profitable ones with potential investors, and equilibria in which no innovation occurs.

The central insight of the analysis can be described as follows: Innovation intermediaries provide an opportunity for potential users and financiers of new inventions to economize on a critical component of innovation decisions under uncertainty: the expertise to locate new, external inventions and to overcome the problem of sorting 'profitable' from 'unprofitable' ones. As noted by Cohen and Levinthal (1989), acquiring this expertise involves considerable sunk costs. Thus, potential investors may benefit from sharing expertise. We find that an intermediary may be able to exploit economies of sharing expertise.

The analysis reveals that the extent to which economies of sharing are realized depends critically on two factors. First, the possibility to use success-based payments, and second, the number of available inventions. If the payoff for the intermediary can be tied to the investors' payoff, e.g., by running royalties, we show that the intermediary will select as many profitable inventions as possible (i.e., employ a "non-wasteful" selection strategy). Because this strategy increases the probability that an investor will obtain a high return to investment, the usage of success-based payments tends to increase investors' valuation of the intermediation service. Nevertheless, simply tying the intermediary's payoff to that of the investor is not sufficient to ensure that the intermediary's revenue will be large enough to recoup the cost of expertise. In addition, a critical mass must be reached on the input side. We show that an increase in the size of the invention pool can increase investors' willingness to pay for intermediation activity. However, as it turns out, this relationship need not necessarily be monotonic. The reason is a multiplicity of consistent equilibrium selection strategies, thus leading to multiple equilibria in the innovation subgames. Nevertheless, we demonstrate that intermediation in innovation can become viable, considering all costs, if the number of inventions is above some threshold level. The findings in our 
model are consistent with empirical evidence.

Furthermore, we analyze welfare properties of the innovation equilibria. While intermediation helps reducing the uncertainty problem, social efficiency may be limited by the intermediary's incentive to offer inventions of low profitability whenever there are no profitable inventions available, and by the high potential for coordination failure due to the multiplicity of equilibria. Social inefficiencies may also arise from competition among multiple intermediaries. We find that combining intermediation services, e.g. in regional networks, may be a way to improve social welfare.

The work most closely related in the intermediation literature appears to be that of Biglaiser (1993) and Lizzeri (1999). Both authors examine models where sellers and buyers are asymmetrically informed about the quality of a product. Biglaiser shows that the concern for reputation may induce an infinitely lived middleman who buys and resells goods to inspect the quality and signal it through his choice of price. ${ }^{4}$ Lizzeri investigates the extent to which quality can be signalled by means of a certification agency, taking into account that the agency may benefit from information manipulation. In both papers, the intermediary serves as a device for signalling high quality, but plays no active role otherwise. In contrast, we focus on a situation where initially no party has private information, so signalling of information is no issue in our paper. Instead, we analyze the incentives of an intermediary to invest in expertise and make proper use of it. Caillaud and Jullien (2001) analyze a model with intermediaries who are able to match suitable trading partners. Competition in registration and transaction fees is shown to give rise to dominant firm equilibria that are similar to the equilibria with concentrated intermediation in our model. However, in contrast to our paper, an intermediary is endowed with expertise by assumption which makes truthful matching always credible in their model.

Related is also the work on venture capitalists by Chan (1983). He too considers a model where potential investors must decide whether or not to invest in an innovative venture. His focus, however, is different from ours. We focus on the problem of uncertainty about the characteristics of a new invention and the corresponding question of whether an intermediary can reduce this uncertainty, whereas Chan does not address the uncertainty problem but instead focuses on the moral hazard problem with inventor effort and the corresponding question of whether an intermediary can induce inventors to expend more effort. $^{5}$

\footnotetext{
${ }^{4}$ The analysis is extended in Biglaiser and Friedman (1999) by allowing for free-entry competition between intermediaries.

${ }^{5}$ For a recent study of the role of intermediaries in mitigating moral hazard and opportunism, see Dixit (2001).
} 
In the innovation literature, the paper closest to ours seems to be that of Jensen and Thursby (2001). They too consider a theoretical model of university-industry technology transfer. ${ }^{6}$ Their model assumes that there is a single new invention and a single potential adopter and that a TTO is responsible for executing the technology transfer. Their central finding is that royalty licensing can alleviate a moral hazard problem with inventor effort. By contrast, we consider a situation with multiple inventions and multiple investors and explore the reasons why intermediaries such as TTOs emerge. Our paper hence complements their work.

In the next section we develop the formal intermediation model. Section 3 presents the equilibrium analysis. In Section 4 we consider competition between intermediaries. Section 5 endogenizes the inventor involvement in the process of new technology adoption. Section 6 concludes with a discussion of empirical evidence, policy implications, and directions for future research.

\section{Model}

In the following we will exemplify the issue of intermediation in innovation in the context of a university-industry technology transfer model. Intermediation by venture capitalists, underwriters, and technology-based incubators could be modeled along similar lines. An analysis of these innovation intermediaries is discussed in Section 6.

Consider a situation with a finite set of inventors $N \equiv\{1, \ldots, n\}$, each of which has one invention, and a finite set of firms, $K \equiv\{1, \ldots, k\}$. Without loss of generality we can assume that $k \leq n$ (i.e. there are at least as many inventions as there are firms). Inventors need an investor for the commercialization of their invention, while firms seek to commercialize one promising new invention. ${ }^{7}$ The cost of commercializing an invention is $A>0$. Each firm $j \in K$ is characterized by an efficiency parameter $\beta_{j}>0$, with $\beta_{1} \geq \cdots \geq \beta_{k}$. All parties are risk-neutral.

One of the key features of new inventions is that their return to adoption is uncertain. To capture this feature, let $q$ denote the quality of an invention and assume that the adoption return is $q=V_{H}$ with probability $p$, and $q=V_{L}$ with probability $(1-p)$, where

\footnotetext{
${ }^{6}$ For empirical studies of technology transfer from universities and federal laboratories to industry, see Jaffe (1989), Audretsch and Stephan (1996), Henderson et al. (1998), Zucker et al. (1998), Jaffe and Lerner (1999), Siegel et al. (2000), Mowery and Ziedonis (2001).

${ }^{7}$ That is, we assume that each potential investor has financial funds for one innovation. An alternative interpretation is that, even if a firm can invest in more than one invention, $k$ represents the total number of innovation opportunities.
} 
$0<p<1$ and $0<V_{L}<V_{H} \cdot{ }^{8}$ Firms are unable to observe the quality level of an invention before they make the investment. If firm $j$ adopts an invention of quality $q_{i}$, it obtains a return $\beta_{j} q_{i}{ }^{9}$ We make the following two assumptions:

$$
\begin{gathered}
\beta_{1}\left[p V_{H}+(1-p) V_{L}\right]<A \\
\beta_{k} V_{H}>A
\end{gathered}
$$

Assumption A1 implies that even the most efficient firm would not adopt an invention of unknown quality. Assumption A2 implies that even the least efficient firm would adopt a high-quality invention when there is no uncertainty. Under these assumptions a potential market for invention fails to exist due to uncertainty about the profitability of adoption.

Now we introduce an intermediary, called the technology transfer office (TTO). We assume that the TTO is also risk neutral. The TTO can choose to make a sunk investment of $C>0$ to acquire an expertise that enables it to locate a new invention and recognize whether it is of high or low quality. $C$ can for instance be interpreted as the cost of human capital development or the cost of hiring personnel with professional competence in specialized fields. For simplicity, we neglect any variable costs of evaluating inventions, which seems fairly in accordance with empirical observations. As noted for instance by Cohen and Levinthal $(1989,1990)$, the cost of acquiring the ability to assess the value of new, external knowledge is typically substantial compared to immediate costs of information processing, which are often negligible. ${ }^{10}$

We are interested in a situation where the inventions are owned by a university and the university's TTO is responsible for executing the technology transfer to firms. In Section 4 we extend the basic model by allowing for multiple TTOs. The participation of faculty-inventors in university-industry technology transfer is considered in Section 5.

\footnotetext{
${ }^{8}$ The assumption that there are only two types of inventions is made to simplify the analysis. One can verify that the results of the paper continue to hold in the case of more than two types.

${ }^{9}$ Notice that we capture the efficiency of a firm through the value that the firm can create by adopting any invention. Efficiency on the other hand can also be captured through lower cost of developing and implementing an invention. In other words, we could have multiplied the adoption cost $A$ with a firmspecific efficiency parameter. Our results continue to hold in such a case.

${ }^{10} \mathrm{We}$ can verify that the results obtained in this paper continue to hold when there is a small cost of expertise per invention. Furthermore, the results also hold if the investment in expertise would enable the intermediary to obtain only a noisy (but informative) signal about the commercial value of new inventions, or if firms have some a priori information about the profitability of adopting an invention. The critical point is that, even if firms possess some information, the intermediary can choose to get better informed by making the investment $C>0$.
} 
The timing and nature of decisions by the TTO and firms are as follows. At date 0, the TTO decides whether to invest in expertise or not. The investment is observable. If it does not invest, the game ends and payoffs to all players are zero. If it invests, it observes the number of high-quality inventions that are available, denoted by $m$, where $m \leq n$. At date 1 , the TTO and firms play the following innovation game. The strategy for the TTO is a selection rule, denoted by $\sigma$. The TTO offers each firm $j \in K$ an invention according to its selection rule $\sigma$, and charges a fraction $\rho_{j}$ of the expected revenue accruing to the firm once it adopts the new technology, where $\rho_{j} \in(0,1] .{ }^{11}$ Formally, let $\sigma=\left\{s_{j}\right\}_{j \in K}$ be a set of functions, where $s_{j}:\{1, \ldots, n\} \rightarrow\{0,1\}$ for each $j \in K$. Here $s_{j}(m)=1$ means that firm $j \in K$ receives a high-quality invention, and $s_{j}(m)=0$ means that firm $j \in K$ receives a low-quality invention, when there are $m$ high-quality inventions. We assume that $\sum_{j=1}^{k} s_{j}(m) \leq m$ and $k-\sum_{j=1}^{k} s_{j}(m) \leq n-m$. At date 2 , each firm accepts or rejects the TTO's offer. Each firm has a belief about the TTO's selection choice. We denote the set of firms that participate in technology transfer by $P$, and the cardinality of $P$ by $\# P$. A participating firm invests $A$ to implement the invention, and payoffs are realized.

Let $\pi_{j}$ denote the probability that firm $j \in P$ will receive a high-quality invention, given $s_{j}$. That is,

$$
\pi_{j}\left(s_{j}\right)=\sum_{m=1}^{n} s_{j}(m) \lambda(m),
$$

where

$$
\lambda(m)=\left(\begin{array}{c}
n \\
m
\end{array}\right) p^{m}(1-p)^{n-m}
$$

Let $\tilde{\pi}_{j}$ be firm $j$ 's belief that it will obtain a high-quality invention, and $\tilde{P} \subseteq K$ denote the subset of firms that the TTO believes will participate in technology transfer. The expected payoff of a firm $j \in K$, from participation is then

$$
\left(1-\rho_{j}\right) \beta_{j}\left[\tilde{\pi}_{j} V_{H}+\left(1-\tilde{\pi}_{j}\right) V_{L}\right]-A,
$$

and the expected payoff of the TTO is

$$
\sum_{j \in \tilde{P}} \rho_{j} \beta_{j}\left[\pi_{j} V_{H}+\left(1-\pi_{j}\right) V_{L}\right]-C
$$

\footnotetext{
${ }^{11}$ Note that the model covers the two most frequently used licensing methods for university inventions, royalty (fee per unit of output) and equity contracts (Jensen and Thursby, 2001; Jensen et al., 2001). For simplicity we neglect the possible output distortion induced by royalties through their effect on the marginal cost of production.
} 
if it invests in expertise. We assume that firm $j$ is willing to participate in technology transfer whenever its expected payoff from adoption, as given by (1), is nonnegative. Similarly, the TTO is willing to invest in expertise whenever its expected payoff from such an investment, as given by (2), is nonnegative. So, a necessary condition for intermediation activity is

$$
\sum_{j=1}^{k} \beta_{j} V_{H}-k A>C
$$

which states that the cost of expertise is smaller than the maximal social gains from technology transfer. We assume that A3 holds.

\section{Intermediation equilibria}

In the absence of an intermediary, firms have no incentive to adopt an invention in the situation characterized by assumptions A1 and A2 due to uncertainty about the profitability of adoption. The key question is whether this uncertainty can be credibly resolved through intermediation activity. We are interested in the subgame-perfect equilibrium of the overall game where equilibrium strategies constitute a Bayesian Nash equilibrium in every subgame. In the following we will show that intermediation equilibria with innovation may indeed exist under assumptions A1 through A3. Working backwards, we start with the examination of the innovation game at date 1 .

\subsection{Non-wasteful equilibrium}

We first characterize the intermediary's equilibrium selection strategy in the continuation game after its investment in expertise. For this we make use of the following definition:

Definition 1 Suppose $P$ is the set of firms that participate in technology transfer in an equilibrium of the innovation game. A non-wasteful equilibrium is an equilibrium in which $\sum_{j \in P} s_{j}(m)=\min \{m, \# P\}$.

In a non-wasteful equilibrium each high-quality invention is assigned to some participating firm, as long as there are fewer high-quality inventions than firms. In the case where there are more high-quality inventions than participating firms, all firms receive a high-quality invention.

Proposition 1 Suppose the TTO invests in expertise, then all Bayesian Nash equilibria of the innovation game in which at least one firm participates are non-wasteful. 
Proof. Suppose in a Bayesian Nash equilibrium of the game the set of firms that participate is given by $P$, with $P \neq \emptyset$.

Case (i): $0<m \leq \# P$. Suppose towards a contradiction that $\sum_{j \in P} s_{j}(m)<m$. Since $P \neq \emptyset$, this implies that there exists some $j^{\prime} \in P$ such that $s_{j^{\prime}}(m)=0$. Consider the following deviation by the TTO: $\hat{s}_{j^{\prime}}(m)=1$. Clearly such a deviation is feasible. The probability that firm $j^{\prime}$ will receive a high-quality invention, given the deviation, is

$$
\begin{aligned}
\hat{\pi}_{j^{\prime}} & =\sum_{l \neq m} s_{j^{\prime}}(l) \lambda(l)+\hat{s}_{j^{\prime}}(m) \lambda(m) \\
& =\sum_{l \neq m} s_{j^{\prime}}(l) \lambda(l)+\lambda(m)
\end{aligned}
$$

Now, for any selection of contracts $\left\{\rho_{j}\right\}_{K}$, we have $\hat{\pi}_{j^{\prime}}>\pi_{j^{\prime}}$ which implies that

$$
\rho_{j^{\prime}} \beta_{j^{\prime}}\left[\hat{\pi}_{j^{\prime}} V_{H}+\left(1-\hat{\pi}_{j^{\prime}}\right) V_{L}\right]>\rho_{j^{\prime}} \beta_{j^{\prime}}\left[\pi_{j^{\prime}} V_{H}+\left(1-\pi_{j^{\prime}}\right) V_{L}\right]
$$

for all $\rho_{j^{\prime}} \in(0,1]$. Clearly, the TTO's payoff increases, which is a contradiction. Hence, $\sum_{j \in P} s_{j}(m)=m$.

Case (ii): $m>\# P$. A similar line of arguments establishes that $\sum_{j \in P} s_{j}(m)=\# P$.

Proposition 1 reveals that an intermediary who has invested in expertise always benefits from choosing a non-wasteful selection strategy, given it believes that at least one investor will participate in the innovation game. This result highlights the crucial role of successbased compensation for intermediation in innovation: because the intermediary gains when a commercialized invention yields a high return, it has an incentive to select as many high-quality inventions as possible. By contrast, it would have no such incentive under a fixed-fee payment scheme. This implies that even though the intermediary has no means to credibly reveal the true nature of an invention, potential investors can infer from the usage of success-based payments that selecting inventions of high commercial value is a priority for the intermediary. The finding can account for the frequent usage of successbased licensing methods such as royalty (fee per unit of output) and equity contracts in university-industry technology transfer (Jensen and Thursby, 2001; Jensen et al., 2001). ${ }^{12}$

The next lemma states an important property of a non-wasteful equilibrium when the number of inventions tends to infinity.

\footnotetext{
${ }^{12}$ Fixed fees in university-industry licensing contracts are mainly used to cover the fixed costs of patent applications. As Jensen and Thursby (2001) have shown the usage of fixed fees can also be explained by the presence of risk aversion.
} 
Lemma 1 Suppose $P \subseteq K$ is the set of firms that participate in a non-wasteful equilibrium of the innovation game, then $\lim _{n \rightarrow \infty} \pi_{j}=1$ for all $j \in P, P \subseteq K$.

Proof. Note that,

$$
\begin{aligned}
\pi_{j}\left(s_{j}\right) & =\sum_{m=1}^{n} s_{j}(m) \lambda(m) \\
& =\sum_{1 \leq m<k} s_{j}(m) \lambda(m)+\sum_{k \leq m \leq n} s_{j}(m) \lambda(m) .
\end{aligned}
$$

In a non-wasteful equilibrium, $\sum_{m \geq k} s_{j}(m) \lambda(m)=\sum_{m \geq k} \lambda(m)$. Thus,

$$
\pi_{j}\left(s_{j}\right) \geq \sum_{k \leq m \leq n} \lambda(m) \rightarrow 1 \text { as } n \rightarrow \infty
$$

Thus, when the number of inventions gets large enough, the probability that a licenseefirm obtains a high return approaches 1 in any equilibrium of the innovation game in which at least one firm participates. In contrast, note that under a fixed-fee payment scheme the probability that a licensee-firm obtains a high return would not approach 1 in every equilibrium in which at least one firm participates when the number of inventions goes to infinity. Note further that in the absence of an intermediary the probability of obtaining a high return always remains $p$, irrespective of any variation in the size of the invention pool.

The lemma is now used to prove our first main result.

Proposition 2 If $n$ is large enough, there are two types of subgame-perfect equilibria. One involves investment in expertise by the TTO and participation of all firms. The other involves no investment in expertise by the TTO and no participation of any firm.

Proof. Consider first the continuation game where the TTO has invested in expertise. Suppose there is one firm that participates. So we know by Proposition 1 that in this case the TTO will choose a strategy $\sigma$ so that the equilibrium will be non-wasteful. We now show that in this case in fact all firms participate when $n$ is large enough.

Let $\left\{\rho_{j}^{\prime}\right\}_{K}$ be the set of contracts such that

$$
\left(1-\rho_{j}^{\prime}\right) \beta_{j}\left[\tilde{\pi}_{j} V_{H}+\left(1-\tilde{\pi}_{j}\right) V_{L}\right]-A=0
$$

for all $j \in K$. We show that $\left\{\rho_{j}^{\prime}\right\}_{K}$ exists if $n$ is large enough. Let $\beta_{k} V_{H}-A=\Delta$. By assumption A2, $\Delta>0$ is such that the least efficient firm will participate if it obtains a 
high-quality technology for sure. Choose $\hat{n}$ large enough such that

$$
\beta_{k}\left(\sum_{k \leq m \leq \hat{n}} \lambda(m)\right) V_{H}+\beta_{k}\left(1-\sum_{k \leq m \leq \hat{n}} \lambda(m)\right) V_{L}-A>\frac{\Delta}{2}>0 .
$$

Note that $\tilde{\pi}_{j}\left(s_{j}\right) \geq \sum_{k \leq m \leq \hat{n}} s_{j}(m) \lambda(m)$. In a non-wasteful equilibrium, we have that $\sum_{k \leq m \leq \hat{n}} s_{j}(m) \lambda(m)=\sum_{k \leq m \leq \hat{n}} \lambda(m)$. So $\tilde{\pi}_{j}\left(s_{j}\right) \geq \sum_{k \leq m \leq \hat{n}} \lambda(m)$. This means that

$$
\begin{aligned}
& \beta_{j} \tilde{\pi}_{j}\left(s_{j}\right) V_{H}+\beta_{j}\left(1-\tilde{\pi}_{j}\left(s_{j}\right)\right) V_{L}-A \\
\geq & \beta_{k}\left(\sum_{k \leq m \leq \hat{n}} \lambda(m)\right) V_{H}+\beta_{k}\left(1-\sum_{k \leq m \leq \hat{n}} \lambda(m)\right) V_{L}-A \\
> & \frac{\Delta}{2}>0
\end{aligned}
$$

since $\beta_{j} \geq \beta_{k}$ for any $j \in P, P \subseteq K$. Thus, $\rho_{j}^{\prime}$ can be chosen small enough such that

$$
\left(1-\rho_{j}^{\prime}\right) \beta_{j}\left[\tilde{\pi}_{j}\left(s_{j}\right) V_{H}+\left(1-\tilde{\pi}_{j}\left(s_{j}\right)\right) V_{L}\right]-A \geq 0
$$

Hence, if $n$ is large enough, there is a contract $\rho_{j}^{\prime}$ such that condition (4) is satisfied for firm $j$, and since $j$ is arbitrary, $\left\{\rho_{j}^{\prime}\right\}_{K}$ exists. That is, if offered $\rho_{j}^{\prime}$, each firm $j \in K$ participates. It is easy to check that for $n$ large enough $\left\{\rho_{j}^{\prime}\right\}_{K}$ is indeed part of every subgame-perfect equilibria in which the TTO invests in expertise. This follows from Proposition 1 and since the TTO's expected payoff is increasing in $\rho_{j}$ and \#P.

To complete this part of the proof we show that the TTO finds it optimal to invest in expertise if $n$ is large enough, provided that $P \neq \emptyset$, i.e. it expects at least one firm to participate in the continuation game. From Lemma 1, $n$ can be chosen large enough such that for any $\varepsilon \in[0,1]$,

$$
\beta_{j}\left[\pi_{j} V_{H}+\left(1-\pi_{j}\right) V_{L}\right] \geq(1-\varepsilon) \beta_{j} V_{H}
$$

Hence,

$$
\sum_{j=1}^{k} \beta_{j}\left[\pi_{j} V_{H}+\left(1-\pi_{j}\right) V_{L}\right] \geq(1-\varepsilon) \sum_{j=1}^{k} \beta_{j} V_{H}
$$

We can write the TTO's revenue as

$$
\sum_{j=1}^{k} \beta_{j}\left[\pi_{j} V_{H}+\left(1-\pi_{j}\right) V_{L}\right]-\sum_{j=1}^{k}\left(1-\rho_{j}^{\prime}\right) \beta_{j}\left[\pi_{j} V_{H}+\left(1-\pi_{j}\right) V_{L}\right]
$$




$$
\begin{aligned}
& =\sum_{j=1}^{k} \beta_{j}\left[\pi_{j} V_{H}+\left(1-\pi_{j}\right) V_{L}\right]-\sum_{j=1}^{k}\left(1-\rho_{j}^{\prime}\right) \beta_{j}\left[\tilde{\pi}_{j} V_{H}+\left(1-\tilde{\pi}_{j}\right) V_{L}\right] \\
& =\sum_{j=1}^{k} \beta_{j}\left[\pi_{j} V_{H}+\left(1-\pi_{j}\right) V_{L}\right]-k A \\
& \geq(1-\varepsilon) \sum_{j=1}^{k} \beta_{j} V_{H}-k A
\end{aligned}
$$

where the first equality follows from $\tilde{\pi}_{j}=\pi_{j}$ in a non-wasteful equilibrium, the second equality follows from the assumption that the firms will participate whenever their expected payoff is non-negative and the third (weak) inequality from (6). Furthermore, for any $C$ that satisfies assumption A3 we can choose $\varepsilon$ small enough such that

$$
(1-\varepsilon) \sum_{j=1}^{k} \beta_{j} V_{H}-k A>C
$$

is satisfied. Consequently, the TTO chooses to invest in expertise.

Now reconsider the subgame that follows the investment in expertise by the TTO. We will construct a Bayesian Nash equilibrium of the continuation game in which no firm participates. One such equilibrium would be the one where the TTO chooses to offer only available low-quality inventions, together with any set of licensing contracts. Since $n$ is large enough by hypothesis, in this case all firms would receive a low-quality invention with high probability. If firms have compatible beliefs, i.e. they assign probability 0 to the TTO playing a strategy $\sigma$ such that the equilibrium will be non-wasteful, they prefer not to participate. Thus, given this equilibrium of the subgame, the TTO chooses not to invest in expertise in the first place.

This completes the proof, since we have shown that, if $n$ is large enough, in any subgame-perfect equilibrium either all firms participate and the TTO invests in expertise, or no firm participates and the TTO does not invest in expertise.

Proposition 2 reveals that the feasibility of success-based payments, while necessary, is not sufficient to guarantee effective intermediation activity. Required is also a critical mass on the input side. As we demonstrate, a larger pool of commercializable technologies can make the probability that unprofitable inventions are selected small in any non-wasteful equilibrium. An increase in the pool size thus tends to enhance potential investors' willingness to participate in the innovation game. However, as the proof of Proposition 2 also reveals, this relationship need not be necessarily monotonic. The reason is the multiplicity 
of consistent equilibrium selection strategy beliefs, leading to multiple non-wasteful equilibria in the innovation game. Nevertheless, we demonstrate that the expected revenue for the TTO will be large enough to recoup the cost of expertise if the number of inventions exceeds a threshold level, and intermediation in innovation becomes viable.

The intuition behind the result is that intermediaries can provide an opportunity for investors to collectively share the expertise that is needed to overcome the problem of locating new technologies and sorting profitable from unprofitable ones. ${ }^{13}$ If the number of inventions is large enough, it pays for an intermediary to invest in expertise and reduce the uncertainty problems surrounding the adoption of new technology in the economy. Technology transfer then occurs in a situation where no transfer would occur without an intermediary.

Note however that social efficiency in the market for inventions may still be limited by the intermediary's incentive to recommend inventions of low profitability whenever it does not bear the cost of adopting the inventions. Note further that the innovation game admits equilibria in which more efficient firms invest in unprofitable inventions while less efficient firms invest in profitable ones. In addition, inefficiencies may result if coordination between firms and the intermediary as envisioned in the innovation equilibria does not occur. As the proposition shows, there always exists an equilibrium in which neither the intermediary nor potential investors are active. This equilibrium arises when potential investors assign probability 0 to the intermediary employing a non-wasteful strategy, and the intermediary expects the set of participating investors to be empty. Fortunately, the equilibrium without innovation appears to be rather fragile. It can be shown that for $n$ large enough every sequential equilibrium involves investment in expertise by the TTO and participation by all firms.

\subsection{Efficient equilibrium}

In the following we will identify a particular equilibrium in which the gains from innovation are maximized.

Definition 2 The efficient strategy is a strategy $\sigma$ such that $s_{j}(t)=1$ for all $j \leq t$. The efficient equilibrium is the equilibrium in which the TTO uses the efficient strategy.

In the efficient equilibrium each high-quality invention is assigned to the most efficient firms as long as there are fewer high-quality inventions than firms. In the case where there

\footnotetext{
${ }^{13}$ Kranton and Minehart (2001) identify economies of sharing in a different context. They show that buyer-seller networks can exploit economies of sharing productive capacity of sellers.
} 
are more high quality inventions than firms, all firms receive a high-quality invention.

Non-wasteful equilibrium allows us to characterize the participation decision of firms only when the TTO has access to a large invention pool. Apart from being intuitively plausible, efficient equilibrium also allows us to characterize the participation decision of firms when the invention pool is not very large. To be specific, define $\alpha$ by $\beta_{1}\left[\alpha V_{H}+(1-\alpha) V_{L}\right]=$ $A$. Now let $\hat{n}$ be the smallest integer such that

$$
\alpha \leq \sum_{m=1}^{\hat{n}}\left(\begin{array}{c}
\hat{n} \\
m
\end{array}\right) p^{m}(1-p)^{\hat{n}-m} .
$$

Thus $\hat{n}$ is the minimum number of inventions that would make it profitable for the most efficient firm to participate when it for sure gets a high-quality invention if there is one. If the invention pool is smaller than this, it can not be profitable for any firm to participate.

The next proposition establishes the existence of a unique (up to relabelling of nonparticipating firms) efficient equilibrium, and provides a characterization of firm participation in technology transfer.

Proposition 3 Suppose $n \geq \hat{n}$. There exists a unique efficient equilibrium with $\hat{k} \leq k$ such that all firms $j \leq \hat{k}$ license an invention if the TTO invests in expertise. Moreover, the TTO invests in expertise if

$$
\sum_{j=1}^{\hat{k}} \beta_{j}\left[\hat{\pi}_{j} V_{H}+\left(1-\hat{\pi}_{j}\right) V_{L}\right]-\hat{k} A \geq C
$$

where

$$
\hat{\pi}_{j}=\sum_{m=j}^{n}\left(\begin{array}{c}
n \\
m
\end{array}\right) p^{m}(1-p)^{n-m}
$$

is the probability that each licensee-firm receives a high-quality invention in the efficient equilibrium.

Proof. Suppose that the TTO is using an efficient strategy, and whenever there is a positive expected surplus, offering contracts that give zero expected profits to firms if they participate. Otherwise the TTO offers any contract, and all such contracts give a negative expected payoff to the relevant firm. By definition of $\hat{n}$ the most efficient firm has a positive expected surplus and under the preceding strategy it clearly participates if the TTO invests in expertise and uses an efficient strategy. Therefore the equilibrium set of participating firms is $P \neq \emptyset$. Now suppose towards a contradiction that there are firms 
$k_{1}<k_{2} \leq k$ such that $k_{1} \notin P$ but $k_{2} \in P$. The expected surplus for $k_{1}$ is positive since the expected surplus for $k_{2}$ is non-negative under the strategy of TTO. Thus firm $k_{1}$ also finds it profitable to participate, contradiction. It is easy to see that the TTO can not benefit from deviating from the efficient strategy once it invests in expertise. This establishes the first claim. The second claim follows immediately from the first one.

The efficient equilibrium, if it exists, weakly Pareto-dominates all other equilibria in the sense that no firm is worse off and the TTO is strictly better off. The efficient equilibrium may therefore be regarded as a focal point in the game on which firms and TTO coordinate. Clearly, if the license revenue obtainable for the TTO is not large enough to recoup the cost of expertise, any equilibrium with technology transfer will fail to exist.

For the efficient equilibrium it is now shown that an increase in the number of inventions monotonically increases the number of licenses and hence the license revenue obtainable for the TTO. The reason is that, under the efficient selection strategy, the probability that the TTO selects a high-quality invention for any given firm is monotonically increasing in the size of its invention pool.

Proposition 4 In the efficient equilibrium, the number of licenses $\hat{k}$ is a monotone increasing function in the number of inventions $n$.

Proof. In an efficient equilibrium, we have

$$
\pi_{j}(n)=\sum_{l=j}^{n}\left(\begin{array}{l}
n \\
l
\end{array}\right) p^{l}(1-p)^{n-l}
$$

which is a monotone increasing function in $n$. To see this note that

$$
\left(\begin{array}{c}
n+1 \\
l
\end{array}\right)=\left(\begin{array}{l}
n \\
l
\end{array}\right)+\left(\begin{array}{c}
n \\
l-1
\end{array}\right)
$$

for $l \leq n$. Using this equality we can see that,

$$
\pi_{j}(n+1)-\pi_{j}(n)=\left(\begin{array}{c}
n \\
j-1
\end{array}\right) p^{j}(1-p)^{n-j+1}>0 .
$$

The result follows immediately.

The evidence given in Siegel et al. (2000) appears to be consistent with the efficient equilibrium. Using a database of 113 U.S. universities, Siegel et al. find that the number

of disclosed inventions has a positive effect on both the number of licenses as well as the TTO's license revenue. 
An attractive feature of the efficient equilibrium is that it maximizes not only the licensing revenue for the TTO but also the number of licenses. Note that in the efficient equilibrium a firm participates only when positive surplus is generated from its participation, given that all firms that are more efficient are participating. Therefore there is no other allocation that would achieve a greater number of licenses. In this sense, even when the TTO's main objective is maximizing the number of licenses, it could not do better than what it achieves in the efficient equilibrium. Thus committing to maximizing revenues and playing the efficient equilibrium achieves multiple objectives for the TTO. ${ }^{14}$ Since licensing revenues are maximized, this income may be used for further research, and this is done in a way that the number of licences is maximized.

\section{Competition between intermediaries}

In this section we consider a situation with multiple intermediaries. One might expect competition to lead to lower gains from intermediation and hence a lower volume of innovation investments. While a complete analysis of the effects of competition between intermediaries is beyond the scope of the present paper, a simple extension of our university-industry technology transfer framework suggests that this need not be the case. Rather, the innovation investments as envisioned in the efficient equilibrium (Proposition 3) is always an equilibrium outcome in the case of multiple intermediaries. However, we will show that competition between intermediaries may also be a source of inefficient innovation investments.

Suppose there are two universities, $i=1,2$, each with its own TTO, TTO 1 and TTO 2 , respectively. The sequence of decisions is like that of the model in Section 2. At date 0 , the TTOs simultaneously decide whether to invest in expertise or not. The investment is observable. If neither of them invests, the game is over and payoffs to all players are zero. If TTO $i$ invests, it observes the number of high-quality inventions, denoted by $m_{i}$, that are available in its invention pool $n_{i}$, where $m_{i} \leq n_{i}$. At date 1 , the TTOs and firms play the following game. The strategy for TTO $i$ is a selection rule, denoted by $\sigma_{i}$. Each TTO $i$ offers each firm $j \in K$ an invention according to its selection rule $\sigma_{i}$, and charges a royalty rate $\rho_{j}^{i} \in(0,1]$ for the license. Formally, let $\sigma_{i}=\left\{s_{j}\right\}_{j \in K}$ be a set of

\footnotetext{
${ }^{14}$ The recent survey of major U.S. universities by Jensen et al. (2000) reveals that the most important objective to a TTO is the generation of licensing revenue. $71 \%$ of the respondents (either directors or license officers of the TTOs) said that it is extremely important, and only one respondent indicated that it is not important. The second most important objective is the number of inventions commercialized, followed closely by the number of licenses.
} 
functions, where $s_{j}:\left\{1, \ldots, n_{i}\right\} \rightarrow\{0,1\}$ for each $j \in K$. Here $s_{j}\left(m_{i}\right)=1$ means that firm $j$ receives a high-quality invention from TTO $i$, and $s_{j}\left(m_{i}\right)=0$ means that firm $j$ receives a low-quality invention from TTO $i$, when there are $m_{i}$ high-quality inventions. We assume that $\sum_{j=1}^{k} s_{j}\left(m_{i}\right) \leq m_{i}$, and $k-\sum_{j=1}^{k} s_{j}\left(m_{i}\right) \leq n_{i}-m_{i}$. At date 2 , each firm accepts at most one license offer (or rejects both offers). Each firm has a belief about the TTOs selection rules. We denote the cardinality of each set of participating licensee-firms $P_{i}$ by $\# P_{i}$. A participating firm invests $A$ to implement the new technology, and payoffs are realized.

Let $\pi_{j}^{i}$ be the probability that firm $j \in P_{i}$ will receive a high-quality invention from TTO $i$, given $s_{j}$, and let $\tilde{\pi}_{j}^{i}$ be firm $j$ 's belief about this probability. The expected payoff of a firm $j \in P_{i}$ is

$$
\left(1-\rho_{j}^{i}\right) \beta_{j}\left[\tilde{\pi}_{j}^{i} V_{H}+\left(1-\tilde{\pi}_{j}^{i}\right) V_{L}\right]-A .
$$

Let $\tilde{P}_{i} \subset K$ denote the subset of firms that TTO $i$ believes would license one of its inventions. The expected payoff of TTO $i$ is then

$$
\sum_{j \in \tilde{P}_{i}} \rho_{j}^{i} \beta_{j}\left[\pi_{j}^{i} V_{H}+\left(1-\pi_{j}^{i}\right) V_{L}\right]-C
$$

if it invests in expertise.

Just like in the model in Section 2, the game of competing intermediaries has multiple subgame-perfect equilibria due to the large strategy space of the TTOs. In the following we restrict attention to situations in which the TTOs are constrained to employ only certain kinds of selection strategies:

1. Efficient equilibria, in which the TTOs commit to the efficient selection strategy, and firms' beliefs are compatible with these strategies.

2. Specialization equilibria, in which the TTOs commit to license as many high-quality inventions as possible to firms of a certain type, and firms' beliefs are compatible with these strategies.

\subsection{Efficient equilibria with multiple intermediaries}

Proposition 3 showed that in the case of a monopoly TTO there exists a unique equilibrium where intermediation implements efficiency in technology transfer. In this section we demonstrate that the equilibrium identified in Proposition 3 remains an equilibrium when there is competition among TTOs. Competition may however also give rise to another, less efficient equilibrium. 
Suppose that each TTO, $i=1,2$, commits to the efficient strategy $\sigma_{i}$, and suppose firms' beliefs are compatible with this selection rule. Let $\underline{n}$ be the infimum of the number of inventions available to a TTO such that all firms are guaranteed to participate in the efficient equilibrium of the monopoly game. Such $\underline{n}$ exists by Proposition 4 . We are interested in the effect of competition in situations where $n_{i} \geq \underline{n}$ for at least one TTO. First we consider the case where universities are symmetric with respect to their invention pools, and then proceed to analyze the case of asymmetric invention pools.

Suppose that $n_{1}=n_{2} \geq \underline{n}$. Thus if both TTOs invest in expertise, firm $j$, faced with a contract offer from each TTO, expects to get a high-quality invention from each of them with the same probability. Hence, firm $j$ 's best response is to contract with TTO $i$ if

$$
\left(1-\rho_{j}^{i}\right) \beta_{j}\left[\tilde{\pi}_{j}^{i} V_{H}+\left(1-\tilde{\pi}_{j}^{i}\right) V_{L}\right]-A \geq 0 \text { and } \rho_{j}^{i}<\rho_{j}^{-i}
$$

where $\rho_{j}^{-i}$ is the royalty rate offered by the other TTO, denoted by TTO $-i$. That is, each firm prefers a licensing contract with a lower royalty rate to one with a higher royalty rate. ${ }^{15}$ Faced with the same expected quality/royalty offer, we assume that the firm contracts with TTO $i$ with probability $1 / 2$ and with TTO $-i$ with probability $1 / 2$. The next proposition characterizes the subgame-perfect equilibrium outcome of the overall game when $n_{1}=n_{2} \geq \underline{n}$.

Proposition 5 Suppose $n_{1}=n_{2} \geq \underline{n}$. There exists no subgame-perfect efficient equilibrium in which both TTOs engage in technology transfer. There exists a subgame-perfect efficient equilibrium in which only one TTO invests in expertise and all firms participate if $C$ is not too high.

Proof. Assume, to the contrary, that there exists a subgame-perfect efficient equilibrium in which both TTOs invest in expertise. Consider the associated continuation game, in which each TTO chooses a royalty rate, $\rho_{j}^{i}$, for each firm $j \in K$. A necessary condition for the existence of a Bayesian Nash equilibrium in this subgame is $\rho_{j}^{1}=\rho_{j}^{2}=0$ for all $j \in K$, for otherwise, one TTO could raise its payoff by slightly undercutting the rival's offer. That is, the TTOs face Bertrand competition with respect to each single firm $j$. Clearly, the licensing revenue obtainable from each firm $j$ and hence the total revenue for

\footnotetext{
${ }^{15}$ This subsection thus considers the extreme case where inventions from different universities are treated as perfect substitutes. This is of course not always true, but it is likely to be valid whenever there exist alternative techniques for the same purpose, e.g. alternative ways to test a drug, and whenever firms are not too specialized on certain technology fields before adoption. We deal with specialization equilibria in the next subsection.
} 
each TTO $i$ is zero. Thus, given one TTO invests in expertise in the first stage, investment is never profitable for the other TTO. This contradiction establishes the first claim of the proposition. From this, Propositions 3 and the fact that $n_{1}=n_{2} \geq \underline{n}$, the second claim follows immediately.

The proposition implies that investment by both intermediaries cannot be supported as a subgame-perfect equilibrium despite the initial symmetry of the game. The intuition is the following. In the equilibrium of the technology transfer game that follows the investment by both TTOs, each firm contracts with the TTO that offers the lowest royalty rate. Hence the TTOs engage in a bidding contest with respect to each single firm. As a result the firm obtains the entire surplus. There is hence no way for a TTO to recoup the investment costs. On the other hand, as shown in the previous section, intermediation is clearly attractive for a single TTO as long as the other one remains inactive. The result reveals that a TTO's incentive to invest in expertise depends crucially on the rival TTO's investment choice.

Suppose next that $n_{2}<\underline{n} \leq n_{1}$. That is, only TTO 1 can ensure participation of all firms should the rival TTO remain inactive.

Proposition 6 Suppose $n_{2}<\underline{n} \leq n_{1}$. There exists a unique $\underline{n}^{\prime}$ with $\underline{n}^{\prime}<\underline{n}$ if $C$ is not too high such that:

(i) For $n_{2}<\underline{n}^{\prime} \leq \underline{n}$, there exists a unique subgame-perfect efficient equilibrium. It involves investment in expertise only by TTO 1 and participation by all firms.

(ii) For $\underline{n}^{\prime} \leq n_{2}<\underline{n}$, there exist two subgame-perfect efficient equilibria: one in which only TTO 1 invests and all firms participate, and another in which only TTO 2 invests and some but not all firms participate. There exist no other subgame-perfect efficient equilibria.

Proof. Suppose that TTO 2 has invested in expertise. Also suppose that $n_{2}<\underline{n}$. By Proposition 4, the number of participating firms is a monotone increasing function in $n_{2}$ in the efficient equilibrium of the technology transfer game. This means that there must be a unique $n_{2}$, say $\underline{n}^{\prime}$, where $\underline{n}^{\prime}<\underline{n}$, such that the available surplus obtainable for TTO 1 from investing in expertise and competing with TTO 2 in a Bertrand fashion is large enough to recoup TTO 1's cost of expertise whenever $n_{2}<\underline{n}^{\prime}$.

(i) Suppose $n_{2}<\underline{n}^{\prime} \leq \underline{n}$. Since $\underline{n} \leq n_{1}$, there exists a subgame-perfect efficient equilibrium in which only TTO 1 invests in expertise and all firms participate. This follows from arguments similar to the ones made in the proof of the previous proposition. Suppose 
now that both TTOs invest in expertise. Since each TTO $i$ employs the efficient strategy $\sigma_{i}$, and since $n_{2}<\underline{n} \leq n_{1}$ by hypothesis, it follows that for all firms the probability of getting a high quality invention from TTO 1 is higher than from TTO 2. This means that these firms will contract with TTO 2 only if it offers a royalty rate that is low enough. Since $n_{2}<\underline{n}^{\prime}$ there is a cutoff level of efficiency such that, for the firms less efficient than that cutoff TTO 2 can not offer a low enough royalty rate to induce their participation. For firms that are more efficient than the cutoff firm such a royalty rate is strictly positive. Thus, TTO 1 has incentive to slightly undercut TTO 2, and they will engage in Bertrand type competition. In either case, TTO 2's payoff is zero. Consequently, TTO 2 has no incentive to invest in expertise in the first place, thus contradicting the hypothesis that there is a subgame-perfect efficient equilibrium in which both TTOs invest in expertise.

Now, assume that there exists a subgame-perfect efficient equilibrium in which only TTO 2 invests in expertise. Since TTO 2 employs the efficient strategy $\sigma_{2}$, and since $n_{2}<\underline{n}$, the candidate equilibrium involves non-participation by some firms. Since $n_{2}<\underline{n^{\prime}}$, by definition of $n^{\prime}$, TTO 1 has an incentive to deviate by investing in expertise. This, however, contradicts the hypothesis that there is another efficient equilibrium in which only TTO 2 invests in expertise. The proof of statement 1 is hence complete.

(ii) The statement for the case of $\underline{n}^{\prime} \leq n_{2}<\underline{n}$ follows straightforwardly from similar arguments.

The analysis reveals that the market for university inventions tends to favor concentrated intermediation. Proposition 6 suggests that the identity of the active TTO is uniquely determined when the differences between the universities in terms of their invention output is sufficiently large. In this case the larger university will provide the intermediation service for the economy. This may explain why some universities form regional networks and share a common TTO, such as for example Access Technology Across Indiana (ATAIN), a statewide alliance by universities in Indiana, including Indiana State University, Indiana University, and Purdue University.

On the other hand, the proposition also shows that intermediation by the TTO with the smaller invention pool and non-participation by some firms may be a possible equilibrium outcome whenever the difference in invention pools is not large enough. There is hence the possibility of a welfare loss.

\subsection{Specialization equilibria}

Specialization is often observed in markets with intermediaries. Sometimes specialization involves the investment in different kinds of expertise. For example, one TTO may special- 
ize in biotechnology, whereas another one may specialize in communication technology. On the other hand, we show here that this is not necessarily the case, and specialization may be just an equilibrium phenomenon where each TTO commits to license to an arbitrary but different group of firms. That is, specialization may arise even if "true" specialization in terms of acquiring an expertise for certain fields of technology is not possible.

Consider a partition of firms into two sets, $G_{1}$ and $G_{2}$ with $G_{1} \cap G_{2}=\emptyset$, and $G_{1} \cup G_{2}=$ $K$. That is, the groups of firms are disjoint sets and each firm is a member of one or the other group, e.g., $G_{1}$ includes all odd-numbered firms and $G_{2}$ all even-numbered firms. We denote the cardinality of $G_{1}$ and $G_{2}$ by $\# G_{1}$ and $\# G_{2}$, respectively. Let $G_{1}$ be TTO 1 's priority group, and $G_{2}$ that of the other TTO. We make use of the following definition. For each $G \subseteq K$, define $G^{m}$ to be the set of the $m$ most efficient firms in $G$. (If $m>\# G$, then $G^{m}=G$.)

Definition 3 The specialization strategy of TTO $i, i=1,2$, is a strategy $\sigma_{i}$ such that (i) $s_{j}\left(m_{i}\right)=1$ for each $j \in G_{i}^{m_{i}}$, and (ii) and $s_{j}\left(m_{i}\right)=1$ for each $j \in G_{3-i}^{\left(m_{i}-\# G_{i}\right)}$ if $m_{i}>\# G_{i}$.

Note that in the specialization equilibrium each TTO assigns as many high-quality inventions as possible to the most efficient firms in its own priority group, and if there are more high-quality inventions than firms in that group, it assigns each remaining highquality invention to the most efficient firms in the other TTO's priority group.

We now show that the model admits a subgame-perfect specialization equilibrium. This equilibrium is supported by compatible firm beliefs. That is, each firm believes that allocating the available high-quality inventions to firms $j \in G_{i}, G_{i} \subset K$, is a priority for TTO $i$. To ensure the existence of the equilibrium, we make the following restrictions on the size of each TTO's invention pool. First, assume that $n_{i} \geq \hat{n}_{G_{i}}$, where $\hat{n}_{G_{i}}$ is the size of the invention pool that is necessary to make participation profitable for the most efficient firm $j \in G_{i}$ in the efficient equilibrium of the monopoly game when this firm for sure gets the good invention from TTO $i$ if there is one, $i=1,2 .{ }^{16}$ Second, let $\underline{n}_{G_{i}}$ be the infimum of $n_{i}$ such that the most efficient firm in $K \backslash G_{i}$ is left with non-negative surplus in the specialization equilibrium. Assume that $n_{i}<\underline{n}_{G_{i}}, i=1,2 .{ }^{17}$

\footnotetext{
${ }^{16}$ If the invention pool is smaller, it can not be profitable for any firm $j \in G_{i}$ to obtain a license from TTO $i$ under the specialization strategy.

${ }^{17}$ The upper bound on $n_{i}$ is due to the fact that if $n_{i}$ gets larger the probability that firms of the nonpriority group obtain a high-quality invention gets larger. Hence, for large enough $n_{i}$ the specialization strategy coincides with the efficient strategy. We use $\underline{n}_{G_{i}}$ to simplify matters.
} 
Proposition 7 Suppose $\hat{n}_{G_{i}} \leq n_{i}<\underline{n}_{G_{i}}, i=1,2$. There exists a subgame-perfect specialization equilibrium with a unique $\hat{k}_{i} \leq \# G_{i}$ such that each firm $j \in G_{i}^{\hat{k}_{i}}$ licenses from TTO $i$ if $C$ is not too high.

Proof. Consider the continuation game where both TTOs have invested in expertise. If firms' beliefs are compatible, it is easy to check that the described equilibrium involves a set of licensing contracts that satisfy

$$
\left(1-\rho_{j}^{i}\right) \beta_{j}\left[\tilde{\pi}_{j}^{i} V_{H}+\left(1-\tilde{\pi}_{j}^{i}\right) V_{L}\right]-A=0
$$

for any firm $j \in G_{i}^{\hat{k}_{i}}, i=1,2$. To see this, note that since $n_{i}<\underline{n}_{G_{i}}, i=1,2$, each firm $j \in G_{i}$ believes that the probability that it obtains a high-quality invention from TTO $-i$ is too low to make licensing from $-i$ profitable for any $\rho_{j}^{-i}$. That is, faced with a contract offer from each TTO, a firm $j \in G_{i}$ always prefers a license from $i$ over a license from $-i$. There is hence no profitable deviation for any TTO by choosing a different royalty rate, given the other TTO's selection strategy and compatible firm beliefs.

We will now check whether any TTO can gain by deviating from both, its selection strategy and royalty choice. Let $j^{\prime}$ be the least efficient firm $j \in G_{i}$ that obtains a highquality invention from TTO $i$ in the candidate equilibrium. Clearly, the best possible deviation consists of a reallocation of a high-quality invention from $j^{\prime}$ to a firm $j^{\prime \prime} \in G_{3-i}$ with $j^{\prime \prime}<j^{\prime}$, i.e. a firm of the rival TTO's priority group that is more efficient that $j^{\prime}$. Since $n_{i}<\underline{n}_{G_{i}}$, however, there exists no contract $\rho_{j^{\prime \prime}}^{i}$ that would induce firm $j^{\prime \prime}$ to license from TTO $i$ given sceptical belief against $i$. To see this, note that the described deviation does not change the firm's belief and therefore its participation decision as firms are unable to observe the TTO's selection strategy. That is, firm $j^{\prime \prime}$ expects to obtain a low-quality invention from TTO $i$ with such a high probability that licensing from $i$ is not profitable for that firm. Clearly, the same argument holds for any firm $j \in G_{3-i}$. Hence the TTO cannot gain by deviating from the specialization strategy.

We have thus shown that the specialization strategies are best responses to each other and constitute an equilibrium in the innovation game that follows each TTO's investment in expertise. Clearly, it is required that $C$ must not be too large for the expertise investment to be profitable for each TTO. The proof is complete.

The result demonstrates that specialization to certain target groups can emerge in a competitive market for university inventions. The basic features which lead to specialization are the possibility to partition the set of firms in different subsets, an intermediatesized invention pool of each university, and sufficiently low costs of expertise. Under these 
circumstances the TTOs can avoid Bertrand competition in the contract stage. This allows them to recoup the cost of expertise up to a certain level, despite the presence of an active rival.

What are the welfare consequences of specialization? Our analysis has revealed that specialization may cause a waste of high-quality inventions ex post if $m_{i}>\# G_{i}$ and $m_{3-i}<\# G_{3-i}$, i.e. if for one TTO the number of high-quality inventions exceeds the number of firms in its priority group, and vice versa for the other TTO. Given pessimistic beliefs of firms in the rival TTO's priority group, a TTO will not be able to match them with its remaining $\left(m_{i}-\# G_{i}\right)$ high-quality inventions. That is, the social gains from innovation may not be maximized ex post in the specialization equilibrium. Moreover, it is worth noting that specialization involves investments by two TTOs where one investment would have been sufficient to solve the problem of uncertainty for the economy if the investor had access to both invention pools. Combining TTO services may therefore be a way to improve social welfare.

\section{Intermediation with inventor involvement}

The above analysis abstracts from the inventors' role in the innovation process by treating the probability that an invention is of high quality as exogenous. In this section we endogenize this probability by assuming that it depends on the inventor's development effort and giving each inventor the choice of whether to expend such effort or not. We thus essentially combine our model of Section 2 with that of Jensen and Thursby (2001).

We redefine the probability that an invention is of high quality as $p_{i}$ for invention $i$. Following Jensen and Thursby, we assume that the probability of success depends on the inventor's development effort, which is not contractible. We make the simplifying assumption that $p_{i}=p$ if inventor $i$ invests $E>0$, and $p_{i}=0$ otherwise, where $p \in(0,1]$. Furthermore, we replace the assumption on the cost of expertise accordingly by assuming that

$$
\sum_{j=1}^{k} \beta_{j} V_{H}-k(A+E)>C .
$$

The sequence of decisions in the extended framework is as follows. The investment decision by the TTO at date 0 remains as before. At date 1 , the TTO offers each firm $j$ a licensing contract for an invention $i$. The contract now specifies the royalties for the TTO and inventor $i$, denoted by $\rho_{i j}^{T} \in(0,1]$ and $\rho_{i j}^{i} \in(0,1]$, respectively, with $\rho_{i j}^{T}+\rho_{i j}^{i} \leq 1$. At date 2 , firm $j$ accepts or rejects the contract. If it accepts, a development stage follows 
at date 3 in which the inventor $i$ can choose to increase the probability of success by expending efforts in the development of his invention. Since efforts are non-contractible, there is a moral hazard problem with respect to the inventor's effort, exactly as in the model of Jensen and Thursby. Finally, the outcome of the inventor's development effort is observed and the licensee-firm decides whether to invest $A$ for the implementation of the new technology.

Denote the set of participating inventors by $Q \subseteq\{1, \ldots, k\}$. The expected payoff of a firm $j \in P$ is

$$
\left(1-\rho_{i j}^{i}-\rho_{i j}^{T}\right) \beta_{j}\left[\tilde{\pi}_{j} V_{H}+\left(1-\tilde{\pi}_{j}\right) V_{L}\right]-A
$$

the expected payoff of inventor $i \in Q$ is

$$
\rho_{i j}^{i} \beta_{j}\left[\tilde{\pi}_{j} V_{H}+\left(1-\tilde{\pi}_{j}\right) V_{L}\right]-E
$$

and the expected payoff of the TTO is ${ }^{18}$

$$
\sum_{j \in \tilde{P}} \rho_{i j}^{T} \beta_{j}\left[\pi_{j} V_{H}+\left(1-\pi_{j}\right) V_{L}\right]-C
$$

if it invests in expertise.

Inventors and firms will participate whenever they obtain a non-negative payoff. It is not difficult to check that in equilibrium the TTO sets the royalty rates $\rho_{i j}^{i}$ and $\rho_{i j}^{T}$ such that inventors and firms choose to participate and are left with zero surplus. Hence, as in Jensen and Thursby (2001), an inventor will be motivated to engage in the development of the new technology by tying his payoff to that of the licensee-firm. Apart from this, the analysis of the extended game is qualitatively the same as that in Section 3. Moreover, note that an incentive contract could in principle be directly signed between the inventor and the licensee-firm, once a match is made. This suggest that, despite the moral hazard problem with inventor effort, the intermediary's efforts in locating profitable inventions and matching them with potential licensees may be a crucial element of effective technology transfer.

\footnotetext{
${ }^{18}$ In Jensen and Thursby (2001) the TTO maximizes a weighted average of the expected payoffs accruing to the university administration and to the inventor. Since both parties are assumed to benefit from a higher license revenue, one can verify that their main results continue to hold if one assumes that the TTO acts only on behalf of the university, as in our model, and ensures inventor participation via an optimal incentive contract.
} 


\section{Concluding remarks}

Summary The paper offers a new theoretical framework to investigate the organization of innovation investments. Our main finding is that intermediaries can play a crucial role in forming the market for inventions by providing an opportunity to economize on a critical component of innovation decisions under uncertainty: the expertise to locate new inventions and evaluate their commercial value. Using a model of university-industry technology transfer, we have identified conditions under which in equilibrium intermediation in innovation becomes viable: first, success-based compensation schemes must be feasible, and second, the size of the invention pool must be sufficiently large, suggesting the presence of economies of scale.

While we have demonstrated that intermediation can reduce and eliminate the uncertainty problems in the relation between creators and users of new inventions, the study also identifies limitations to the potential efficiency of intermediation activity. First, the intermediary's selection incentives in the market for inventions need not be fully aligned with society's interest. Second, the intermediaries incentive to invest in expertise strongly depends upon the investors' beliefs about the intermediaries selection strategy, introducing a high potential of coordination failure. Indeed, no investment in expertise and no innovation is always an equilibrium of our model. Third, competition between intermediaries may be an additional source of inefficiency. In particular, the identity of the active intermediary may not be optimal from a welfare point of view as well as the market division in the case of specialized intermediaries.

Empirical evidence The findings are supported by empirical evidence. In the context of university-industry technology transfer, Hsu and Bernstein's (1997) case studies suggest that a critical mass of university research activity is often required before a university technology transfer office (TTO) can become active. Using an econometric model, Siegel et al. (2000) estimate the impact of the number of disclosed inventions on the license revenue of TTOs and find strong evidence of increasing returns to scale, which is consistent with our model. In their extensive field research on organizational practices of university TTOs, Siegel et al. find that firms often view the skills and expertise of TTO staff as critical to the effectiveness of university-industry technology transfer. Nevertheless, they also find that some TTOs appear to have little incentives to invest in expertise. Our results may provide a possible explanation for this observation: universities may not have a pool of commercializable technologies large enough to make such an investment attractive.

Of course, there are also cases where firms receive information about the existence 
and value of university inventions from other sources, making intermediation activity less relevant. Audretsch and Stephan (1996) and Zucker et al. (1998), for example, find evidence that the personal characteristics of the inventors, such as the status of being a "star" scientists as measured in terms of research productivity or the receipt of a Nobel prize, can play an important role in attracting firms of the biotechnology industry. On the other hand, such cases appear to be a "right-tail of the distribution" phenomenon, which primarily happens at the very best universities with top scientists in each field. The model developed in this paper thus seems best applicable to "representative" universities and scientists.

Policy relevance The approach developed in this paper may help to understand the effects of a recent regulatory change related to government-sponsored research in the United States, the Bayh-Dole Patent and Trademark Amendments Act of $1980,{ }^{19}$ and frame current government initiatives aimed at copying the Bayh-Dole Act in Germany and Japan. ${ }^{20}$ The Act gave universities the right to retain title to and license inventions resulting from federally funded research and permitted exclusive licensing between universities and industrial firms for these inventions. Since the passage of the Act, an increasing number of U.S. universities began to establish TTOs, and the number of academic licenses increased significantly. ${ }^{21}$ As the analysis in this paper suggests, TTOs can play a crucial role in forming a market for university inventions, provided they obtain sufficient royalty revenue to recoup the investment in expertise. Clearly, the feasibility of running royalties depends on whether universities hold the property rights and are able to license faculty inventions on an exclusive basis. ${ }^{22}$ Thus, effective TTO intermediation appears to became a viable option for universities only after the regulatory changes.

Future research The analysis and results of the paper seem to carry over to the context of underwriters and technology-based business incubators who intermediate between

\footnotetext{
${ }^{19}$ For a discussion of the policy debates on the Bayh-Dole Act and a survey over the related empirical and theoretical literature, see Jaffe (2000).

${ }^{20}$ See, e.g., Süddeutsche Zeitung, "Hochschulen sollen Erfindungen vermarkten", October 27, 2000; The Economist, "The land of disappointments", March 04, 2000.

${ }^{21}$ According to the recent licensing survey by the Association of University Technology Managers (AUTM), AUTM membership increased from 100 TTOs in 1980 to more than 2100 in 1999, and the number of academic licenses increased by $133 \%$ over the period from 1991 to 1999. See the AUTM Web Page, http://www.autm.net.

${ }^{22}$ Without exclusive rights, a firm's incentive to commercialize a new technology tends to be considerably reduced by the possibility of free rider effects (cf. Heller and Eisenberg, 1998; Buchanan and Yoon, 2000).
} 
new start-up firms and potential investors, trying to convince a particular investor that a particular start-up firm is profitable. Venture capitalists differ crucially from TTOs, underwriters, and incubators in that they raise money in advance, promising potential investors to reinvest the money in profitable projects on their behalf. Thus, addressing this form of intermediation would require a modification of our model by considering selection rules that do not depend on the identity of a particular investor and particular invention or project. Nonetheless, we expect the main conclusions of the paper to hold in such a context.

The model could be usefully extended to analyze the effects of intermediation on the interplay between the investor's incentives to commercialize inventions and the inventor's incentives to generate new inventions. It seems also worth exploring specialization incentives of competing intermediaries in a model where inventions differ with respect to their commercial value. For example, the average invention from the medical school may have a larger commercial value than the average invention from, say, the physics department. In the context of university-industry technology transfer, a related potential extension of the model would include competition between universities for talented faculty.

Finally, we would like to emphasize that the timing and nature of innovation are fundamental issues in the understanding of economic growth. Hence, results which draw

on a careful analysis of intermediation in innovation may provide significant implications for policies on economic growth.

\section{References}

[1] Arrow, K. J. (1962), Economic Welfare and the allocation of resources for invention, in The Rate and Direction of Inventive Activity: Economic and Social Factors, National Bureau of Economic Research, Princeton University Press, 609-626.

[2] Audretsch, D. B. and Stephan, P. A. (1996), Company-scientist locational links: The case of biotechnology, American Economic Review 86, 641-652.

[3] Biglaiser, G. (1993), Middlemen as experts, RAND Journal of Economics 24, 212-223.

[4] Biglaiser, G. and Friedman, J. W. (1999), Adverse selection with competitive inspection, Journal of Economics and Management Strategy 8, 1-32.

[5] Buchanan, J. M. and Yoon, Y. J. (2000), Symmetric tragedies: Commons and anticommons, Journal of Law and Economics 43, 1-13. 
[6] Caillaud, B. and Jullien, B. (2001), Competing cypermediaries, European Economic Review 45, 797-808.

[7] Chan, Y.-S. (1983), On the positive role of financial intermediation in allocation of venture capital in a market with imperfect information, Journal of Finance 38, 15431568 .

[8] Cohen, W. M. and Levinthal, D. A. (1989), Innovation and the learning: The two faces of R\&D, Economic Journal 99, 569-596.

[9] Cohen, W. M. and Levinthal, D. A. (1990), Absorptive capacity: A new perspective on learning and innovation, Administrative Science Quarterly 35, 128-152.

[10] Dixit, A. (2001), On the modes of economic governance, Working paper, Princeton University.

[11] Gompers, P. A. and Lerner, J. (1999), The Venture Capital Cycle, MIT Press, Cambridge, Massachusetts.

[12] Heller, M. A. and Eisenberg, R. S. (1998), Can patents deter Innovation? The anticommons in biomedical research, Science 280, no. 5364, 698-701.

[13] Henderson, R., Jaffe, A. B. and Trajtenberg, M. (1998), Universities as a source of commercial technology: A detailed analysis of university patenting 1965-1988, Review of Economics and Statistics 80, 119-127.

[14] Hsu, D. H. and Bernstein, T. (1997), Managing the university technology licensing process: Findings from case studies, Journal of the Association of University Technology Managers 9.

[15] Jaffe, A. B. (1989), Real effects of academic research, American Economic Review 79, 975-70.

[16] Jaffe, A. B. and Lerner, J. (1999), Privatizing R\&D: patent policy and the commercialization of National Laboratory technologies, NBER Working Paper No. 7064.

[17] Jaffe, A. B. (2000), The U.S. patent system in transition: policy innovation and the innovation process, Research Policy 29, 531-557.

[18] Jensen, R. and Thursby, M. (2001), Proofs and prototypes for sale: The licensing of university inventions, American Economic Review 91, 240-259. 
[19] Jensen, R., Thursby, J. G., and Thursby, M. (2001), Objectives, characteristics and outcomes of university licensing: A survey of major U.S. universities, Journal of Technology Transfer 26, 59-72.

[20] Kamien, M. I. and Schwartz, N. L. (1982), Market Structure and Innovation, Cambridge University Press, Cambridge.

[21] Kranton, R. E. and Minehart, D. F. (2001), A theory of buyer-seller networks, American Economic Review 91, 485-508.

[22] Lizzeri, A. (1999), Information revelation and certification intermediaries, RAND Journal of Economics 30, 214-231.

[23] Mowery, D. C. and Ziedonis, A. A. (2001), The geographic reach of market and nonmarket channels of technology transfer: Comparing citations and licenses of university patents, NBER Working Paper No. 8568.

[24] Siegel, D., Waldman, D. and Link, A. (2000), Assessing the impact of organizational practices on the productivity of university technology transfer offices: An exploratory study, NBER Working Paper No. 7256.

[25] Spulber, D. F. (1999), Market Microstructure, Cambridge University Press, Cambridge.

[26] Zucker, L. G., Darby, M. R. and Brewer, M. B. (1998), Intellectual human capital and the birth of U.S. biotechnology enterprises, American Economic Review 88, 290-306. 
Bücher des Forschungsschwerpunkts Markt und politische Ökonomie

Books of the Research Area Markets and Political Economy

Andreas Stephan

Essays on the Contribution of Public Infrastructure to Private: Production and its Political

Economy

2002, dissertation.de

Hans Mewis

Essays on Herd Behavior and Strategic

Delegation

2001, Shaker Verlag

Andreas Moerke

Organisationslernen über Netzwerke - Die

personellen Verflechtungen von

Führungsgremien japanischer

Aktiengesellschaften

2001, Deutscher Universitäts-Verlag

Silke Neubauer

Multimarket Contact and Organizational Design

2001, Deutscher Universitäts-Verlag

Lars-Hendrik Röller, Christian Wey (Eds.)

Die Soziale Marktwirtschaft in der neuen

Weltwirtschaft, WZB Jahrbuch 2001

2001, edition sigma

Michael Tröge

Competition in Credit Markets: A Theoretic

Analysis

2001, Deutscher Universitäts-Verlag

Tobias Miarka

Financial Intermediation and Deregulation:

A Critical Analysis of Japanese Bank-Firm-

Relationships

2000, Physica-Verlag

Rita Zobel

Beschäftigungsveränderungen und organisationales Lernen in japanischen Industriengesellschaften

2000, Humboldt-Universität zu Berlin

http://dochost.rz.hu-berlin.de/dissertationen/zobel-

rita-2000-06-19

Jos Jansen

Essays on Incentives in Regulation and Innovation

2000, Tilburg University

Ralph Siebert

Innovation, Research Joint Ventures, and

Multiproduct Competition

2000, Humboldt-Üniversität zu Berlin

http://dochost.rz.hu-berlin.de/dissertationen/siebert-

ralph-2000-03-23/

Damien J. Neven, Lars-Hendrik Röller (Eds.)

The Political Economy of Industrial Policy in

Europe and the Member States

2000, edition sigma
Jianping Yang

Bankbeziehungen deutscher Unternehmen: Investitionsverhalten und Risikoanalyse 2000, Deutscher Universitäts-Verlag

Christoph Schenk

Cooperation between Competitors -

Subcontracting and the Influence of Information, Production and Capacity on Market Structure and Competition

1999, Humboldt-Universität zu Berlin

http://dochost.rz.hu-berlin.de/dissertationen/schenk-

christoph-1999-11-16

Horst Albach, Ulrike Görtzen, Rita Zobel (Eds.)

Information Processing as a Competitive

Advantage of Japanese Firms

1999, edition sigma

Dieter Köster

Wettbewerb in Netzproduktmärkten

1999, Deutscher Universitäts-Verlag

Christian Wey

Marktorganisation durch Standardisierung: Ein

Beitrag zur Neuen Institutionenökonomik des

Marktes

1999, edition sigma

Horst Albach, Meinolf Dierkes, Ariane Berthoin Antal, Kristina Vaillant (Hg.)

Organisationslernen - institutionelle und

kulturelle Dimensionen

WZB-Jahrbuch 1998

1998, edition sigma

Lars Bergman, Chris Doyle, Jordi Gual, Lars

Hultkrantz, Damien Neven, Lars-Hendrik Röller,

Leonard Waverman

Europe's Network Industries: Conflicting

Priorities - Telecommunications

Monitoring European Deregulation 1

1998, Centre for Economic Policy Research

Manfred Fleischer

The Inefficiency Trap

Strategy Failure in the

German Machine Tool Industry

1997, edition sigma

Christian Göseke

Information Gathering and Dissemination

The Contribution of JETRO to

Japanese Competitiveness

1997, Deutscher Universitäts-Verlag 
Andreas Schmidt

Flugzeughersteller zwischen globalem

Wettbewerb und internationaler Kooperation

Der Einfluß von Organisationsstrukturen auf die

Wettbewerbsfähigkeit von Hochtechnologie-

Unternehmen

1997, edition sigma

Horst Albach, Jim Y. Jin, Christoph Schenk (Eds.)

Collusion through Information Sharing?

New Trends in Competition Policy

1996, edition sigma

Stefan O. Georg

Die Leistungsfähigkeit japanischer Banken

Eine Strukturanalyse des Bankensystems in Japan

1996, edition sigma

Stephanie Rosenkranz

Cooperation for Product Innovation

1996, edition sigma
Horst Albach, Stephanie Rosenkranz (Eds.) Intellectual Property Rights and Global

Competition - Towards a New Synthesis

1995, edition sigma

David B. Audretsch

Innovation and Industry Evolution

1995, The MIT Press

Julie Ann Elston

US Tax Reform and Investment: Reality and

Rhetoric in the 1980s

1995, Avebury

Horst Albach

The Transformation of Firms and Markets:

A Network Approach to Economic Transformation Processes in East Germany

Acta Universitatis Upsaliensis, Studia Oeconomiae Negotiorum, Vol. 34

1994, Almqvist \& Wiksell International (Stockholm) 
Fredrik Andersson

Kai A. Konrad

Andreas Stephan

Tomaso Duso

Steffen Huck

Kai A. Konrad

Wieland Müller

Steffen Huck

Kai A. Konrad

Wieland Müller

Jos Jansen

Astrid Jung

Jonas Björnerstedt Johan Stennek

Manfred Fleischer

Karl Wärneryd

Karl Wärneryd

Steffen Huck

Kai A. Konrad

Michal Grajek

Achim Kemmerling

Andreas Stephan

Suchan Chae

Paul Heidhues

Kai A. Konrad Harald Künemund Kjell Erik Lommerud Julio R. Robledo

Tomaso Duso Lars-Hendrik Röller
Globalization and Human Capital Formation

FS IV $01-01$

Regional Infrastructure Policy and its Impact

FS IV $01-02$ on Productivity: A Comparison of Germany and France

Lobbying and Regulation in a Political Economy: FS IV $01-03$ Evidence from the US Cellular Industry

Merger and Collusion in Contest

FS IV $01-04$

Profitable Horizontal Mergers without Cost

Advantages: The Role of Internal Organization,

Information, and Market Structure

Strategic Information Revelation and Revenue

Sharing in an R\&D Race

(A revision of FS IV 99-11)

FS IV $01-05$

FS IV $01-06$

FS IV $01-07$

Complements?

Bilateral Oligopoly

FS IV $01-08$

Regulierungswettbewerb und Innovation in der chemischen Industrie

FS IV $01-09$

FS IV $01-10$

Preference Adaptation in Winner-Take-All Markets

Information in Conflicts

FS IV $01-11$

FS IV $01-12$

Merger Profitability and Trade Policy

Gender Pay Gap in Poland

FS IV $01-13$

FS IV $01-14$

The Contribution of Local Public Infra-structure to Private Productivity and its Political-Economy: Evidence from a Panel of Large German Cities

Nash Bargaining Solution with Coalitions and the Joint Bargaining Paradox

Geography of the Family

FS IV $01-15$

FS IV $01-16$

Towards a Political Economy of Industrial OrganFS IV $01-17$ ization: Empirical Regularities from Deregulation 
Kai A. Konrad

Roman Inderst Christian Wey

Kai A. Konrad

Helmut Seitz

Klaus Gugler Dennis C. Mueller B. Burcin Yurtoglu Christine Zulehner

Kjell Erik Lommerud Odd Rune Straume Lars Sørgard

Andreas Blume Paul Heidhues

Roman Inders Christian Wey

Klaus Gugler Dennis C. Mueller B. Burcin Yurtoglu

Sven-Olof Fridolfsson Johan Stennek
Investment in the Absence of Property Rights - The Role of Incumbency Advantages

Bargaining, Mergers, and Technology Choice in Bilaterally Oligopolistic Industries

Fiscal Federalism and Risk Sharing in Germany: The Role of Size Differences

The Effects of Mergers: An International Comparison

Downstream Merger with Oligopolistic Input FS IV 01-22 Suppliers

Tacit Collusion in Repeated Auctions

The Incentives for Takeover in Oligopoly

Corporate Governance, Capital Market Discipline and the Returns on Investment

Why Mergers Reduce Profits and Raise Share Prices: A Theory of Preemptive Mergers
FS IV $01-23$

FS IV $01-24$

FS IV $01-18$

FS IV $01-19$

FS IV $01-20$

FS IV $01-21$

FS IV $01-25$

FS IV $01-26$ 
Fredrik Andersson Kai A. Konrad

Lars-Hendrik Röller Christian Wey

Talat Mahmood Klaus Schömann

Jos Jansen

Jos Jansen

Günter Franke Harris Schlesinger Richard C. Stapleton

Tomaso Duso

Johan Lagerlöf

Paul Heidhues

Olivier Cadot Lars-Hendrik Röller Andreas Stephan

Justus Haucap Christian Wey

Heidrun C. Hoppe Emre Ozdenoren
Human Capital Investment and Globalization in Extortionary States

Merger Control in the New Economy

FS IV $02-02$

Die Determinanten der Mirgrationsentscheidung

FS IV $02-03$ von IT-Hochschulabsolventen aus Pakistan Empirische Befunde zur Ausgestaltung der deutschen „Green Card“

The Effects of Disclosure Regulation on Innovative Firms: Common Values

The Effects of Disclosure Regulation on Innovative Firms: Private Values

Multiplicative Background Risk

FS IV $02-06$

On the Politics of the Regulatory Reform: Econometric Evidence from the OECD Countries

On the Desirability of an Efficiency Defense in Merger Control

Contribution to Productivity or Pork Barrel? The Two Faces of Infrastructure Investment

FS IV $02-07$

FS IV $02-08$

FS IV $02-09$

Unionization Structures and Firms' Incentives for Productivity Enhancing Investments

Intermediation in Innovation

FS IV $02-11$ 

Bei Ihren Bestellungen von WZB-Papers schicken

Sie bitte unbedingt einen an Sie adressierten Auf-

kleber mit sowie je paper eine Briefmarke im Wert

von 0,51 Euro oder einen "Coupon Reponse Inter-

national " (für Besteller aus dem Ausland)
Please send a self addressed label and postage stamps in the amount of 0.51 Euro or a "CouponReponse International" (if you are ordering from outside Germany) for each WZB-paper requested

Absender / Return Address:

Wissenschaftszentrum Berlin

für Sozialforschung

Presse- und informationsreferat

Reichpietschufer 50

D-10785 Berlin-Tiergarten

Hiermit bestelle ich folgende(s)

Discussion paper(s):

Please send me the following Discussion paper(s):

Bestell-Nr. / Order no.

Autor/in, Kurztitel /Author(s) / Title(s) in brief 